\title{
The Effect of Thiaminepyrophosphate Levels on Mortality and Morbidity in Patients with Stress Hyperglycemia
}

\section{Author(s)

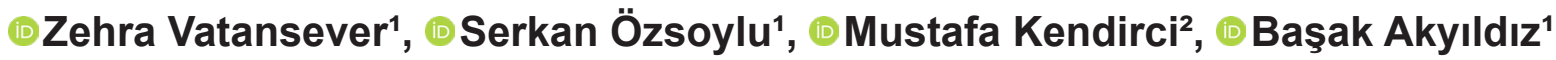

${ }^{1}$ Erciyes University Medical Faculty, Department of Pediatrics, Division of Pediatric Intensive Care Unit, Kayseri, Turkey

Affiliation(s) ${ }^{2}$ Professor in Pediatrics, Erciyes University Medical Faculty, Department of Pediatrics, Division of Pediatric Metabolism and Endocrinology, Kayseri, Turkey

Article

Information
Article Type: Original Articles

Article Group: Pediatric Critical Care Medicine
Received: 24.04 .2020

Accepted: 16.06 .2020

Available Online: 31.07 .2020

\section{Abstract}

The aim of this study is to evaluate the thiamine pyrophosphate deficiency and effects on critical illness hyperglycemia in pediatric intensive care. 126 critically ill children included to the study which applied to Erciyes University Faculty of Medicine, Department of Pediatric Intensive Care Unit (ICU). Age, sex, diagnosis and presence of malnutrition in admission to ICU; Pediatric risk of Mortality III (PRISM III) and Pediatric Logistic Organ Dysfunction (PELOD) scores; mechanical ventilation and length of stay in ICU was evaluated. Blood glucose, thiamine pyrophosphate, cortisol, insulin, C-peptide, HbA1c level, serum lactate in blood gas were analyzed at the time of application. The patients grouped based on blood glucose levels, the group whose glucose level in blood is more than $150 \mathrm{mg} / \mathrm{dl}$ (n:75); PRISM and PELOD scores were high, mechanical ventilation and length of stay in intensive care were longer, thiamine pyrophosphate levels were lower $(p<0.001, p=0.005, p=0.008, p<0.001, p<0.01)$. In case of blood glucose $>150 \mathrm{mg} / \mathrm{dl}(\mathrm{n}: 51)$ and thiamine pyrophosphate $<180 \mathrm{nmol} / \mathrm{l}$ is together; mortality increases 3.342 -fold and the case was statistically significant $(p=0.014)$. The group whose glucose level in blood is more than $150 \mathrm{mg} / \mathrm{dl}$ respectively, insulin, c-peptide and cortisol levels found high and the findings were statistically significant $(p<0.001, p=0.005, p=0.040)$. Stress hyperglycemia is a common situation seen in critically ill patients as a cause of worse clinical outcomes. Identification of stress hyperglycemia due to thiamine deficiency is difficult but it will shed light on the treatment of critically ill children.

Keywords: Critically ill child, morbidity, mortality, stress hyperglycemia, thiamine pyrophosphate

Correspondence: Serkan Ozsoylu, Erciyes University Medical School, Department of Pediatric Intensive Care Unit, Talas Kayseri, Turkey

E-mail: sozsoylu@hotmail.com 


\section{Introduction}

Hyperglycemia is a common pathology in critically ill patients and prevalence is high in pediatric intensive care units. ${ }^{1}$ It is known that increasing blood glucose level above $150 \mathrm{mg} / \mathrm{dl}$ in the first 24 hours of hospitalization is associated with higher mortality rates..$^{2-4}$ Insulin resistance, insulin deficiency, cytokine-associated epinephrine and increased anti-insulin hormones as well as glucagon have been suggested in etiology. ${ }^{5}$ The level and duration of hyperglycemia increases mortality and morbidity as a result of multiple organ insufficiency in both adults and children. ${ }^{1}$ It has been shown that hyperglycemia, which develops as a result of insulin deficiency or resistance in diabetic patients increases endothelial damage and associated organ damage. However, in diabetic patients with thiamine deficiency, it is known that the regulation of blood glucose is more difficult and the related organ damage is much more severe. ${ }^{6}$

In general, thiamine deficiency in children is $7.5 \%$ and in critically ill children is about $28 \% .{ }^{7,8}$ Lactic acidosis which develops in the presence of thiamine deficiency accompanied by liver dysfunction is more severe in patients with sepsis and is associated with mortality due to multiple organ dysfunction. Theoretically, increased metabolic stress due to catabolism is associated with low thiamin levels. ${ }^{9}$ From this point on, the effect of thiamine pyrophosphate level on mortality and morbidity in patients with hyperglycemia at the time of application in pediatric intensive care is more important. We investigate whether thiamin can be hypothesised as a low cost, practical, easy-to-reach effective treatment to reduce mortality and morbidity by using in pediatric intensive care units with hyperglycemic children.

We aimed to evaluate the thiamine pyrophosphate deficiency and effects on critical illness hyperglycemia in pediatric intensive care.

\section{Materials and Methods}

126 critically ill children included to the study which applied to University Hospital. The study was approved by the "Medical Research Local Ethics Committee" of Erciyes University. (approval date: 2013, approval number of 2013-319). We took informed consents from all the parents of the patients. Patients with a history of diabetes mellitus, steroid and $\beta 2$ agonist use were excluded from the study. Age, sex, diagnosis and presence of malnutrition in admission to pediatric intensive care unit; PRISM and PELOD scores; mechanical ventilation and length of stay in ICU was evaluated. Blood glucose, thiamine pyrophosphate, cortisol, insulin, C-peptide, $\mathrm{HbA} 1 \mathrm{c}$ level, serum lactate in blood gas were analyzed at the time of application. Patients were divided into two groups according to their blood glucose values: $<150$ $\mathrm{mg} / \mathrm{dL}$ as group 1 ( $\mathrm{n}: 51)$ and $>150 \mathrm{mg} / \mathrm{dL}$ as group 2 ( $\mathrm{n}: 75)$. 4-6 mg/kg/minute glucose infusion rate was given to patient as a glucose supply.
Venous blood glucose levels were performed in the laboratory. Lactate measurements were performed in Siemens Rapidlab-1265 device.Other laboratory analyses were carried out in the Central Laboratory.

$\mathrm{HbA} 1 \mathrm{c}$ level was evaluated by immunoassay method in Roche COAS-6000 $0.5 \mathrm{ml}$ whole blood sample.

$3 \mathrm{~mL}$ of blood for insulin, cortisol and C-peptide levels were taken into a flat tube and studied with immunoassay method in Roche COAS-8000-2 device.

Thiamine pyrophosphate level was analyzed using HPLC in $2 \mathrm{ml}$ of Agilent HPLC 1100 in EDTA. The level of thiamine pyrophosphate $<180 \mathrm{nmol} / \mathrm{L}$ was considered to be deficiency. ${ }^{10}$

In order to evaluate the mortality risk and morbidity of patients, Pediatric risk of Mortality III (PRISM III) and Pediatric Logistic Organ Dysfunction (PELOD) scores were used.

\section{Statistical analysis}

All statistical analyses were performed in the statistical package Statistical Package for the Social Sciences (SPSS) 22.0. Shapiro-Wilk test was applied to all variables and it was determined whether there was normal or abnormal distribution. The comparison between groups for data with a normal distribution (Insulin, C-peptide, HbA1c) was performed using Student's t-test, and the comparison between groups for data that did not show a normal distribution (Thiamine pyrophosphate, lactate) was performed using the Mann-Whitney $U$ test. Categorical variables were compared by means of a chisquare test. ROC analysis was used to determine the predictive power. $\mathrm{p}<0.05$ was considered statistically significant.

\section{Results}

126 patients who were admitted to pediatric intensive care unit at our hospital with different diagnoses under the age of 18 years were included in this study. Eightyone $(64.3 \%)$ of the patients were male and $45(35.7 \%)$ were female. When groups of patients are evaluated according to their blood glucose level, blood glucose $\leq 150 \mathrm{mg} / \mathrm{dL}$ (Group 1) in the group of 51 patients (14 female, 37 male), $>150 \mathrm{mg} / \mathrm{dL}$ (Group 2) in the group of 75 patients ( 31 girls and 44 boys) were detected. The median age of the Group 1 was 26 and Group 2 was 24 months, respectively, and there was no statistically significant difference between the groups.

Statistically significant difference was found between the groups according to PRISM and PELOD scores at the time of hospitalization according to blood glucose levels. (Table 1)

Insulin, c-peptide and cortisol values were detected statistically significant increase in group 2 and there was no statistically significant difference between the groups in terms of $\mathrm{HbA} 1 \mathrm{c}$ values. Lactate levels were significantly higher and thiamine pyrophosphate levels were significantly lower in patients with blood glucose $>150 \mathrm{mg} / \mathrm{dl}$. (Table 2) 


\section{Table 1}

Demographic features, PRISM and PELOD scores according to blood glucose levels

\begin{tabular}{|c|c|c|c|}
\hline \multirow{2}{*}{ Variables } & \multicolumn{2}{|c|}{ Blood glucose $(\mathrm{mg} / \mathrm{dl})$} & \multirow{2}{*}{ p } \\
\hline & Group 1 n (\%) & Group 2 n (\%) & \\
\hline & $51(\% 40.4)$ & $75(\% 59.6)$ & \\
\hline Age (month) & $26(12-72)$ & $24(7.5-50)$ & 0.05 \\
\hline \multicolumn{4}{|l|}{ Gender } \\
\hline female (n:45) & 14 & 31 & 0.89 \\
\hline male $(\mathrm{n}: 81)$ & 37 & 44 & \\
\hline PRISM & $10.27(2-13)$ & $14(8-22)$ & $<0.001$ \\
\hline PELOD & $10(1-17)$ & $13(10-22)$ & 0.01 \\
\hline $\begin{array}{l}\text { Mechanical } \\
\text { ventilation (day) }\end{array}$ & $10(1-17)$ & $13(10-22)$ & 0.01 \\
\hline $\begin{array}{l}\text { Length of PICU stay } \\
\text { (day) }\end{array}$ & $3(1-7)$ & $6(3-9)$ & $<0.001$ \\
\hline \multicolumn{4}{|l|}{ Admission Diagnosis } \\
\hline Respiratory n (\%) & $14(27.4)$ & $10(13.3)$ & 0,78 \\
\hline Cardiology n (\%) & $9(17.6)$ & $5(6.7)$ & 0,67 \\
\hline Trauma $\mathrm{n}(\%)$ & $10(19.6)$ & $7(9.3)$ & 0,54 \\
\hline Neurological n (\%) & $26(50.9)$ & $4(5.3)$ & $<0.001$ \\
\hline Infection n (\%) & $16(31.3)$ & $9(12)$ & 0,37 \\
\hline Other n (\%) & $12(23.5)$ & $4(5.3)$ & 0,45 \\
\hline
\end{tabular}

Table 2

Hormone, lactate and thiamine pyrophosphate according to blood glucose levels

\begin{tabular}{|c|c|c|c|}
\hline \multirow{2}{*}{ Variables } & \multicolumn{2}{|c|}{ Blood glucose (mg/dl) } & \multirow{2}{*}{ p } \\
\hline & Group 1 n (\%) & Group 2 n (\%) & \\
\hline & $51(\% 40.4)$ & $75(\% 59.6)$ & \\
\hline Insulin (IU/ml) & $5(2.6-9.5)$ & $2.2(0.98-3.46)$ & $<0.001$ \\
\hline C-peptide $(\mathrm{pmol} / \mathrm{ml})$ & $9,5(6.41-23)$ & 3.07 (1.49-5.5) & 0.005 \\
\hline $\mathrm{HbA} 1 \mathrm{c}(\%)$ & $5.1(4.8-5.3)$ & $5.1(4.7-5.4)$ & 0.832 \\
\hline Cortisol (mg/dl) & $35(15.2-53.98)$ & $43.31(29.9-63)$ & 0.040 \\
\hline $\begin{array}{l}\text { Thiamine } \\
\text { pyrophosphate } \\
\text { (nmol/l) }\end{array}$ & $206.74 \pm 31.26$ & $180.47 \pm 37.13$ & $<0.01$ \\
\hline Lactate $(\mathrm{mmol} / \mathrm{l})$ & $2.09 \pm 0.35$ & $3.85 \pm 0.399$ & $<0.01$ \\
\hline
\end{tabular}

38 patients $(30.2 \%)$ had thiamine pyrophosphate levels below $180 \mathrm{nmol} / \mathrm{L}$. When the patient data were evaluated in terms of the relationship between blood glucose level and thiamine pyrophosphate, a negative and moderate correlation was found. $(p=0,001$, rho:0.51) The relationship between thiamine pyrophosphate and blood glucose is shown in Figure 1.

When the blood glucose and thiamine pyrophosphate values of the patients were evaluated to determine the predictive power by ROC analysis, the blood glucose level above $272 \mathrm{mg} / \mathrm{dl}$ and thiamine pyrophosphate below $177 \mathrm{nmol} / \mathrm{l}$ was determined. ROC analysis of the values presented in Table 3 and Figure 2.

When the factors affecting mortality in patients included in the study were evaluated, the mortality for blood glucose $>150 \mathrm{mg} / \mathrm{dl}$ increased 1.875 times but was not statistically significant. In the case of thiamine pyrophosphate $<180 \mathrm{nmol} /$ I, the mortality was 3.025 times higher and was statistically significant. In the present study, the risk of death was found to be 3.342 times higher if both cases were present at the same time and it was statistically significant. (Table 4)

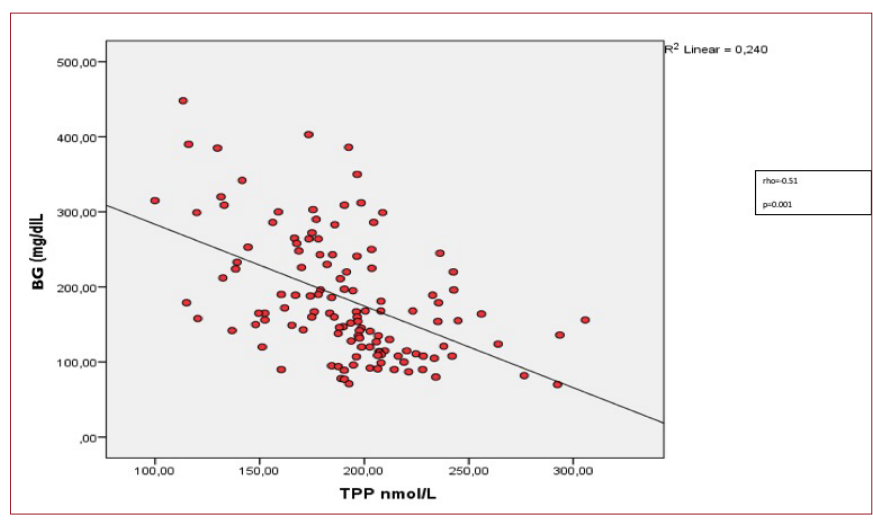

Figure I. The relationship between the level of blood glucose level and thiaminepyrophosphate graph

BG: Blood glucose, TPP: Thiaminepyrophosphate

\section{Table 3 \\ Results of ROC analysis of thiamine pyrophosphate and blood glucose values}

\begin{tabular}{lcc}
\hline Variables & AUC & p \\
\hline Blood glucose & 0.616 & 0.046 \\
Thiaminepyrophosphate & 0.675 & 0.03 \\
\hline
\end{tabular}

AUC: Area under the curve

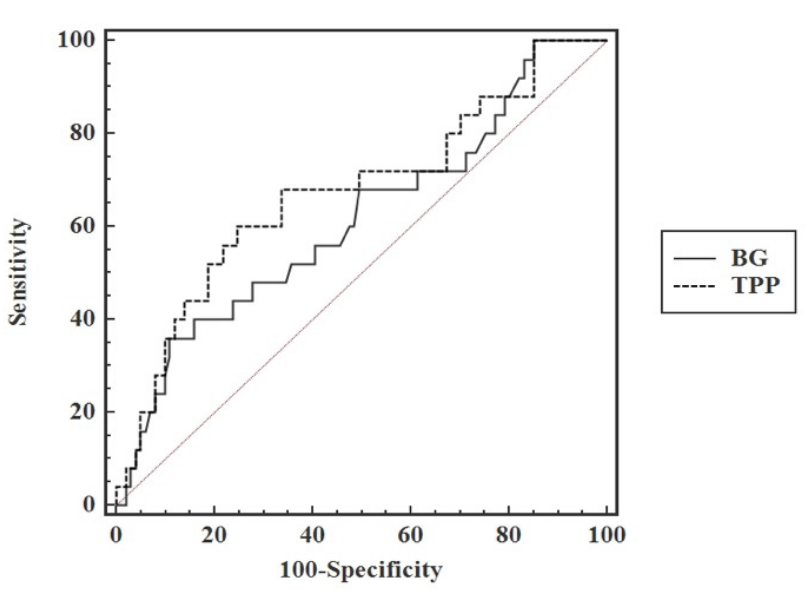

Figure II. ROC analysis of the mortality-related values of thiaminepyrophosphate and blood glucose values

Table 4

Evaluation of The Effect of Blood Glucose Level And Thiamine Pyrophosphate Values On Mortality

\begin{tabular}{lcc}
\hline Variables & OR $(\mathbf{C l}$ \%95) & p \\
\hline Blood glucose $>150 \mathrm{mg} / \mathrm{dl}$ & $1.875(0.67-5.21)$ & 0.228 \\
TPP $<180 \mathrm{nmol} / \mathrm{l}$ & $3.025(1.159-7.896)$ & 0.024 \\
Blood glucose $>150 \mathrm{mg} / \mathrm{dl}$, & $3.342(1.274-8.766)$ & 0.014 \\
TPP $<180 \mathrm{nmol} / \mathrm{l}$ &
\end{tabular}

\section{Discussion}

Although the information about the definition of stress hyperglycemia is not clear, different values are taken as limit in the literature and the data are calculated on these values. In our study, we obtained the limit of stress hyperglycemia as $150 \mathrm{mg} / \mathrm{dL}$, which has the strongest relationship between mortality and morbidity. In the study of 1616 pediatric intensive care patients, the hyperglycemia limit was determined as $200 \mathrm{mg} / \mathrm{dL}$ 
and it was found that the PRISM score was significantly higher in both the deceased and survived patient groups when the blood glucose level was high (>200 mg/dl). ${ }^{11}$ Hirshberg et al ${ }^{12}$ reported a linear relationship between PRISM score and blood glucose level. In a study involving 19 pediatric intensive care patients, the PELOD score of the hyperglycemic group was expressed to be significantly higher. ${ }^{13}$ In our study PRISM and PELOD scores at the admission were evaluated and a statistically significant difference was found between the hyperglycemic and normoglycemic groups and these findings were consistent with the literature.

Ballestero et $\mathrm{al}^{14}$ found that the relationship between hyperglycemia and C-peptide was generally linear, but not associated with hyperglycemia. Preissig et al. ${ }^{13}$ reported C-peptide levels were found to be significantly low in the hyperglycemic group with respiratory and/ or cardiovascular insufficiency. In a study of 29 postoperative pediatric patients, they found there was no relationship between hyperglycemia and cortisol but cortisol levels were higher in the dying patient group. ${ }^{14}$ In our study, insulin, c-peptide and cortisol values were detected statistically significant increase in group 2 and there was no statistically significant difference between the groups in terms of $\mathrm{HbA} 1 \mathrm{c}$ values. According to obtained data, cortisol values were higher in the group with high blood glucose as expected in stress hyperglycemia. In our study, insulin and $C$ peptide levels were measured in parallel with hyperglycemia. This can be explained by the expected insulin resistance in stress hyperglycemia.

The first study on thiamine deficiency in critically ill children was performed by Seear et $\mathrm{al}^{15}$ the thiamine deficiency in 80 well-nourished children was found to be $12.5 \%$. In a study involving 202 patients, thiamine deficiency was reported in $28 \%$ of critically ill children in Brazil. Severe sepsis or septic shock with thiamine deficiency has been reported to be higher in mortality. ${ }^{17}$ In different studies where thiamin levels were evaluated in adult patients with trauma, burns, myocardial infarction, cardiac surgery, renal failure, and refractory syndrome, it has shown that mortality and morbidity increase in different groups of patients with thiamine deficiency. ${ }^{14}$ In the present study 38 patients $(30.2 \%)$ had thiamine pyrophosphate levels below $180 \mathrm{nmol} / \mathrm{L}$.

Lactate levels were significantly higher and thiamine pyrophosphate levels were significantly lower in patients with blood glucose $>150 \mathrm{mg} / \mathrm{dl}$. When thiamine levels are insufficient, pyruvate is unable to be converted to acetyl coenzyme A (by pyruvate dehydrogenase), resulting in impaired aerobic respiration and a compulsory shift to the anaerobic pathway, resulting in elevated serum lactate levels. There are two types of lactic acidosis. Type A is more common in patients with impaired tissue perfusion, with or without hypoxia. Type B lactic acidosis is caused by some drugs, chemicals, toxic compounds or genetic disorders that can cause lactate accumulation. ${ }^{16}$ It is very difficult to say whether the increasing lactate levels in PICU patients is due to thiamine deficiency (type B) or to impaired organ perfusion (type A).

When the blood glucose and thiamine pyrophosphate values of the patients were evaluated to determine the predictive power by ROC analysis, the blood glucose level above $272 \mathrm{mg} / \mathrm{dl}$ and thiamine pyrophosphate below $177 \mathrm{nmol} / /$ was determined. In the present study, it was found that the risk of mortality increased by 1.875 fold for blood glucose and 3.025 fold for TPP and 3.342 fold for mortality if both cases were present at the same time. This suggests that the blood glucose alone may not be sufficient to estimate mortality; especially when it is associated with thiamine deficiency, the mortality is significantly increased.

There are some limitations in our study. Long-term follow up is needed to see if there will be any impairments due to stress hyperglycemia and also the duration of stress hyperglycemia was not considered.

Stress hyperglycemia is a common situation seen in critically ill patients as a cause of worse clinical outcomes. Identification of stress hyperglycemia and causative factors of stress hyperglycemia, it will shed light on the treatment of critically ill children. Although hyperglycemia was not a negative predictive factor for mortality and morbidity alone, clinical results were found to be worse in patients with thiamine deficiency. We demonstrated thiamine deficiency in critically ill children with hyperglycemia. But there is no information about the replacement of thiamine is helpful for the treatment of stress hyperglycemia or not. Further studies are needed to obtain clearer results regarding the results of thiamine supplementation.

Ethics Committee Approval: The study was approved by the "Medical Research Local Ethics Committee" of Erciyes University. (approval date: 2013, approval number of 2013-319).

Informed Consent: Written informed consent was obtained from patients who participated in this study.

Peer-review: Externally peer-reviewed.

Author Contributions: All of the authors declare that they have all participated in the design, execution, and analysis of the paper, and that they have approved the final version

Conflict of Interest: The authors have no conflict of interest to declare.

Financial Disclosure: The authors declared that this study has received no financial support.

\section{References}

1. Van Herpe T, Vanhonsebrouck K, Mesotten D, et al. Glycemic control in the pediatric intensive care unit of Leuven: two years of experience. J Diabetes Sci Technol 2012; 6: 15-21. [CrossRef]

2. Kliegman RM, Stanton B, Game J, et al. Nelson textbook of pediatrics.(20th ed) Saunders Elsevier, New York, 2016: 375-376.

3. Donahey E, Folse S, Jacobi J. Management of Hyperglycemia in Critically III Patients. Pharm Prac News 2013; 48: 126-135. [CrossRef]

4. Verhoeven JJ, Brand JB, van de Polder MM, et al. Management of hyperglycemia in the pediatric intensive care unit; implementation of a glucose control protocol. Ped Crit Care Med 2009; 10: 648652. [CrossRef]

5. Santos L. Stress response in critical illness. Curr Probl Pediatr Adolesc Health Care 2013; 43: 264-272. [CrossRef]

6. Luong KVQ, Nguyen LTH. The impact of thiamine treatment in the diabetes mellitus. J Clin Med Res. 2012; 4: 153-155. [CrossRef] 
7. Lima LFP, Leite HP, de Taddei JACA. Low blood thiamine concentrations in children upon admission to the intensive care unit: risk factors and prognostic significance. Am J Clin Nutr. 2011; 93: 57-61. [CrossRef]

8. Shaw NS, Wang JL, Pan WH, et al. Thiamin and riboflavin status of Taiwanese elementary schoolchildren. Asia Pac J Clin Nutr 2007; 16: 564-571. [CrossRef]

9. Donnino MW, Carney E, Cocchi MN, et al. Thiamine deficiency in critically ill patients with sepsis. J Crit Care. 2010; 25: 576-581. [CrossRef]

10. Mancinelli R, Ceccanti M, Guiducci MS, et al. Simultaneous liquid chromatographic assessment of thiamine, thiamine monophosphate and thiamine diphosphate in human erythrocytes: a study on alcoholics. J Chromatogr B Analyt Technol Biomed Life Sci. 2003; 789: 355-363. [CrossRef]

11. Klein GW, Hojsak JM, Schmeidler J, et al. Hyperglycemia and outcome in the pediatric intensive care unit. J Pediatr 2008; 153: 379-384. [CrossRef]
12. Hirshberg E, Larsen G, Van Duker H. Alterations in glucose homeostasis in the pediatric intensive care unit: Hyperglycemia and glucose variability are associated with increased mortality and morbidity*. Pediatr Crit Care Med. 2008; 9: 361-366. [CrossRef]

13. Preissig CM, Rigby MR. Pediatric critical illness hyperglycemia: risk factors associated with development and severity of hyperglycemia in critically ill children. J Pediatr. 2009; 155: 734739. [CrossRef]

14. Ballestero Y, López-Herce J, González R, et al. Relationship between hyperglycemia, hormone disturbances, and clinical evolution in severely hyperglycemic post surgery critically ill children: an observational study. BMC Endocr Disord. 2014; 14: 25-28. [CrossRef]

15. Manzanares W, Hardy G. Thiamine supplementation in the critically ill. Curr Opin Clin Nutr Metab Care. 2011;14: 610-617. [CrossRef]

16. Luft FC. Lactic acidosis update for critical care clinicians. J Am Soc Nephrol. 2001; 12: 15-19. [CrossRef] 